\title{
Contributions of Flexible-Arch Configurations in Shimenzi Arch Dam: New Evidence from Field Measurements
}

\author{
Jianwen Zhong, Enzhi Wang, Yuande Zhou, Qingbin Li, and Penghui Li \\ State Key Laboratory of Hydroscience and Engineering, Department of Hydraulic Engineering, \\ Tsinghua University, Beijing 100084, China \\ Correspondence should be addressed to Yuande Zhou; zhouyd@mail.tsinghua.edu.cn
}

Received 27 December 2013; Accepted 13 February 2014; Published 19 March 2014

Academic Editor: Fei Kang

Copyright (C) 2014 Jianwen Zhong et al. This is an open access article distributed under the Creative Commons Attribution License, which permits unrestricted use, distribution, and reproduction in any medium, provided the original work is properly cited.

\begin{abstract}
This paper presents a retrospective investigation into the performance of a new type of flexible-arch configurations in Shimenzi arch dam based on the past ten-year-long field measurements. The flexible-arch configurations are mainly comprised of artificial short joints at the middle downstream surface and a middle contraction joint with hinged well and enlarged arch ends with bending joints. Fundamental design considerations of these components are provided, and their contributions to the performance of Shimenzi arch dam are discussed in detail using the monitoring data from joint meters, strain gauges, and thermometers. Some elementary numerical studies have been conducted on a typical arch structure with different arrangements of artificial joints. Both the field data and numerical results prove well the effectiveness of the purposely built short joints and the middle contraction joint on the relaxation of tensile stress mobilization. Field survey data also clearly demonstrate the significance of the hinged well at the upstream side of the middle joint for a continuous arch force transfer.
\end{abstract}

\section{Introduction}

After a long development history of arch dams, which goes back to the Romans in the 1st century BC [1], relative uniformity was achieved for arch dam designs and techniques in the 20th century. As given in many textbooks, arch dam is a type of dam curved in the shape of an arch, with the top of the arch pointing back into the reservoir. For taking the advantage of an arch that is strong in resisting the pushing force of the upstream pool water, arch dams are usually constructed in narrow, steep sided valleys, and they have a high requirement of rock foundations as compared to another widely used type of concrete gravity dam. Commonly, a solid and intact arch has been adopted during the design of most existing arch dams around the world as such a configuration may make best use of the high compressive strength of concrete material.

Field measurements of many arch dams, such as Buffalo Bill dam in America [2], Kolnbrein dam in Austria [3-5], Dragan arch dam [6] and Glen Canyou arch dam [7] in Romania, Cabril dam in Portugal [8], and Xiangshui arch dam [9] in China, demonstrate that the heel and toe regions along a cross-section, as well as the downstream middle part and both ends of an arch layer from a plan view, are most vulnerable to cracks under actual working conditions. The occurrences of these cracks indicate that the development of new configurations in arch is necessary and of great importance, which will definitely lower the risk of cracks and potential failures by water pressure and thermal loads in the operations of arch dams.

Regarding the cause of cracks commonly found in many arch dams, a review of the relevant literature shows that the main factors contributing to the fracture may include (1) inappropriateness of structural design; (2) large and uneven ground settlement due to weak foundations; (3) excessive temperature loads beyond the standard level; (4) shortage of temperature control measures during construction; (5) lack of thermal insulation measures during and after construction. It is one or a combination of the above factors that caused the cracks in these arch dams of various degrees. Rehabilitation activities, more or less, have been undertaken to restore the design functions of these dams.

In order to minimize the occurrence of cracks in arch dams, some new configurations of flexible-arch type have 


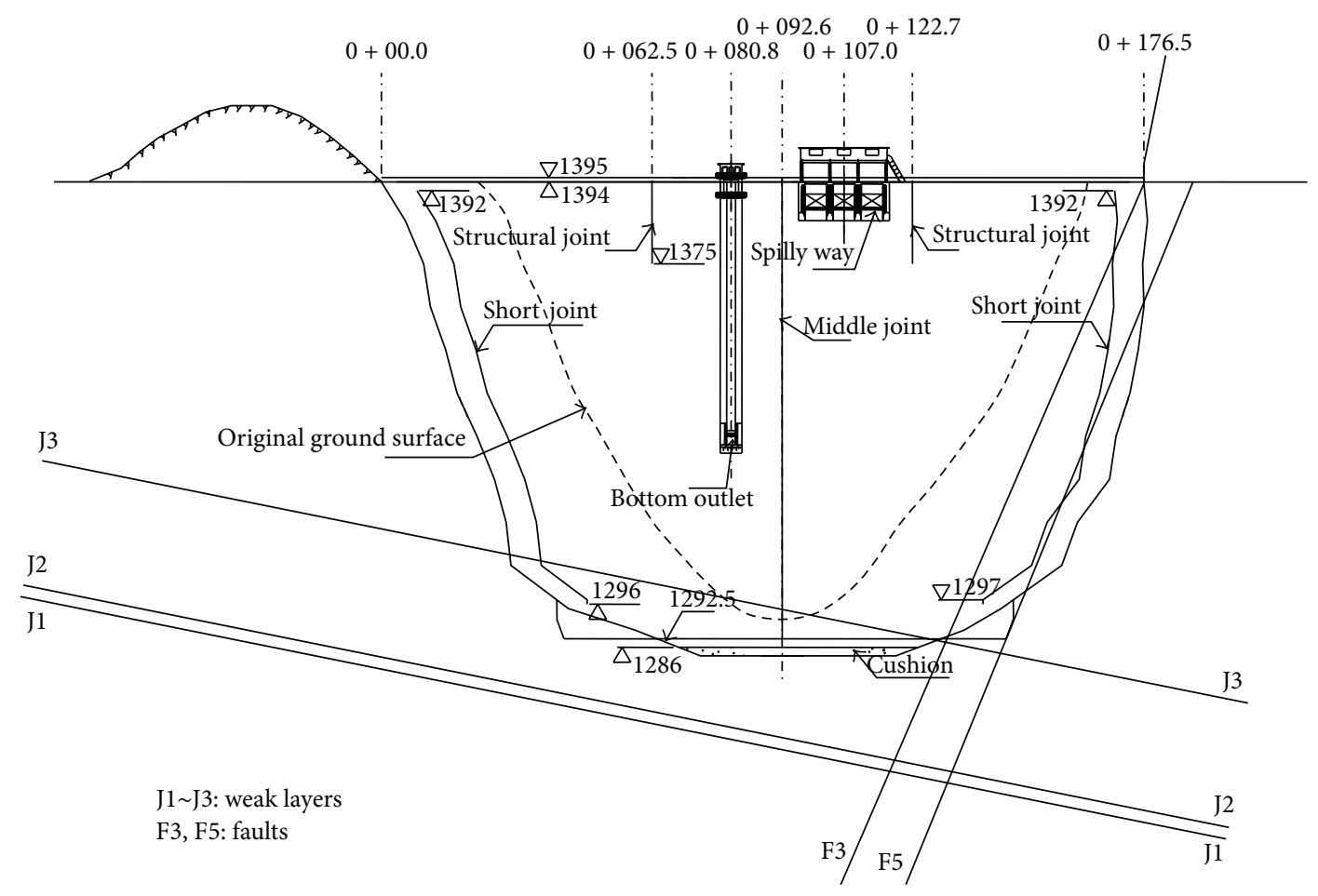

FIgURE 1: The vertical layout of Shimenzi arch dam-foundation system (upstream view).

been developed and implemented in Shimenzi arch dam, a roller compacted concrete arch dam located in the northwest of China. The arch dam was designed and supervised by the Department of Hydraulic Engineering, Tsinghua University, China. The flexible-arch configurations are based on the incorporation of short joints and related treatments at some critical positions of an arch dam, which form a type of partially precracked arch along the elevation direction and make a significant contrast to the intact arch configurations commonly adopted in lots of arch dams. This paper presents a detailed description of the new flexible-arch configurations and investigates their improvement mechanism based on the previous ten-year-long field measurements. Some discussions are then given based on a simple two-dimensional numerical study of arch structure with various short joint arrangements under pressure and thermal loads. In the final section, some concluding remarks are provided.

\section{New Flexible-Arch Configurations in Shimenzi Arch Dam}

2.1. Briefs about Shimenzi Arch Dam. Shimenzi hydraulics project is located in the middle stream of Taxihe River, Xinjiang Province, China. While the main target of this project is for irrigation, it also serves a host of other functions such as flood control, power generating, and ecological balance. The project consists of a roller compacted concrete arch dam, an auxiliary rock fill dam with an inclined clay core, the channels for water diversion and power generation diversion, spillways, and operation buildings. The maximum height of the arch dam is $109 \mathrm{~m}$, with its dam crest being $176.5 \mathrm{~m}$ long and $5 \mathrm{~m}$ wide. The total volume of the reservoir is $5.0 \times$ $10^{7} \mathrm{~m}^{3}$ and normal pool level is $1390 \mathrm{~m}$. A type of doublecurved arch dam is adopted considering the U-shaped valley with a bottom width of 70 86 $\mathrm{m}$. The foundation rocks are mainly made up of conglomerates characterized by loose consolidation and poor cohesion. Particularly, the survey data showed that the saturated compression strength is rather low. The left abutment is cut by an ancient river running in an SN direction, and both sides of the sites are surficially covered by thick loess soils. The site stability condition is poor and a high seismic intensity of 8 degrees is suggested.

Figure 1 shows the layout of the dam-foundation system along the verticaldirection. It can be seen that several main faults and weak layers cut the bedrocks under the concrete dam. Particularly, their strike directions are along the stream direction, which are unfavorable for the antisliding stability of dam abutments. The geometry and typical material zone distributions for the crown cantilever section and the arch layer at $1360 \mathrm{~m}$ level are given in Figure 2. From the width of the base, $31 \mathrm{~m}$, it is indicated that Shimenzi arch dam takes a medium ratio of base width/height ratio (0.284). It can also be seen from Figure 2(a) that the dam cantilever section does not curve downstream quite much, with a nearly vertical boundary near the dam heel, which means lower pressure relief on the stronger, curved arches at lower levels near the abutment, as the foundation rocks are of relatively weak properties from geological survey data. For the lower half of the upstream surface (1286 1345 m level), a $150 \mathrm{~cm}$ thick layer of C-type impermeable roller compacted concrete was adopted for improving the antiseepage property in the vicinity of upstream side. For the upper half, more attention was given 


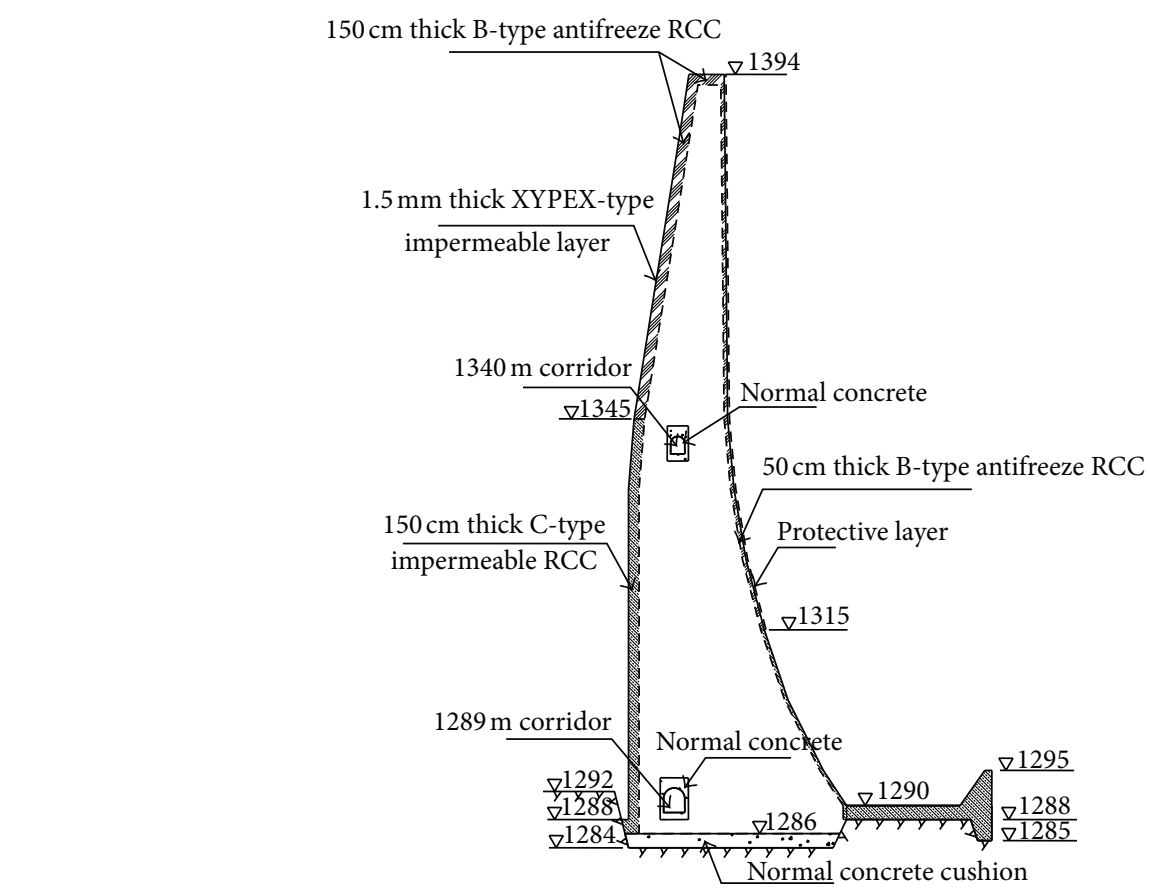

(a) Cantilever section

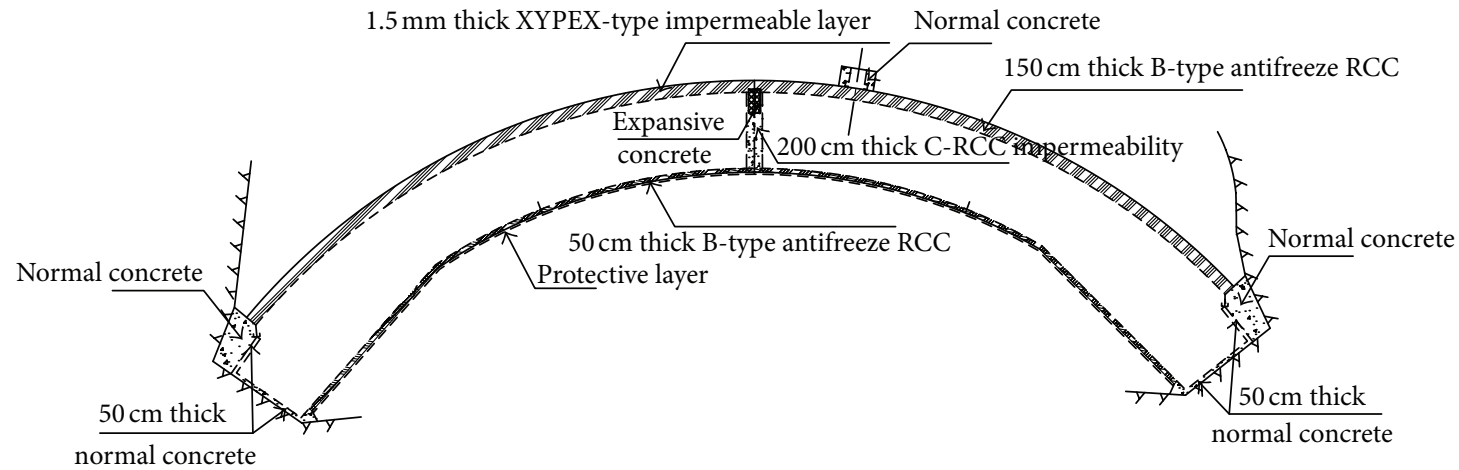

(b) Arch layer at $1360 \mathrm{~m}$ level

FIgURE 2: The geometry and material zone distribution of Shimenzi arch dam.

to its freezing resistance capability and a layer of $150 \mathrm{~cm}$ thick B-type antifreeze (polyurethane insulation coating) roller compacted concrete was applied, on the upstream surface of which one can also note that a $1.5 \mathrm{~mm}$ thick layer of XYPEX was glued for better antiseepage property. Similarly, a layer of polystyrene board was applied at the lower downstream surface ( $1315 \mathrm{~m}$ level below), whilst the upper portion was covered by a $50 \mathrm{~cm}$ thick layer of polyurethane insulation coating.

In the dam construction process, the concrete placement started from early May 1999 on the cushion layer and was followed by consolidation grouting of the rock foundation. The concrete dam reached an elevation of $1308 \mathrm{~m}$ on November 5. Considering the cold weather, the concrete placement was paused from November 1999 to March 2000, and the poured concrete dam parts were cured in water or by a cover of sandy soils. The construction of the dam was restarted again from the end of March 2000 and reached an elevation of $1365 \mathrm{~m}$ at the end of October 2000. It should be noted that the hinged well, which is described in the next section, was grouted at this stage up to an elevation of $1340 \mathrm{~m}$, such that an impoundment of reservoir ahead of schedule could be achieved. From the spring of 2001, the reservoir started the function of water supply for irrigation purpose.

It should be noted that as the Shimenzi hydraulic project is located in the northern part of Tianshan Mountains, the mean atmospheric temperature presents a great variation from the previous long-term measured data. Based on survey data, the mean temperature value can be as high as $18.9^{\circ} \mathrm{C}$ in July and as low as $-12.2^{\circ} \mathrm{C}$ in January of one year, which indicates that a mean gap of $31.1^{\circ} \mathrm{C}$ can be expected for the ambient temperature around the dam structure. Reasonably, it can be inferred from the meteorological data that a great thermal load has to be considered in the construction and operation 
TABLE 1: Fundamental material parameters for the roller compacted concrete and foundation rock of Shimenzi arch dam.

\begin{tabular}{lcc}
\hline \multirow{2}{*}{ Material parameters } & \multicolumn{2}{c}{ Material } \\
& Concrete & Rock \\
\hline Density $\left(\mathrm{kg} / \mathrm{m}^{3}\right)$ & $2.4 \times 10^{3}$ & $2.4 \times 10^{3}$ \\
Modulus of elasticity $(\mathrm{Gpa})$ & 20.0 & $4.0 \sim 10.0$ \\
Poisson's ratio & 0.17 & 0.28 \\
Specific heat $\left(\mathrm{Kcal} / \mathrm{kg} \cdot{ }^{\circ} \mathrm{C}\right)$ & 0.2242 & 0.200 \\
Thermal conductivity $\left(\mathrm{m}^{2} / \mathrm{d}\right)$ & 0.0984 & 0.100 \\
Maximum adiabatic temperature rise $\left({ }^{\circ} \mathrm{C}\right)$ & 12.0 & - \\
Coefficient of linear expansion $\left(1 /{ }^{\circ} \mathrm{C}\right)$ & $6.5 \times 10^{-6}$ & $8 \times 10^{-6}$ \\
\hline
\end{tabular}

design of the arch dam. Particularly, the thermal loads caused by an abrupt temperature drop may trigger cracks in the dam and harm its intactness and strength. Table 1 gives a summary of the fundamental material parameters for the dam concrete and foundation rock. It can be seen that, for the roller compacted concrete, both the elastic modulus and maximum adiabatic temperature rise are relatively low, which can benefit the control of stress concentration, particularly at the tensile region in the dam, and lower the thermal loads by hydration heat generation.

2.2. New Flexible-Arch Configurations. The main content of this paper is on the contributions of flexible-arch configurations introduced in Shimenzi arch dam practice, which are mainly comprised of three components: (1) artificial short joints located near the trisection points of downstream surface; (2) a contraction joint along the cantilever section with hinged well configuration; (3) enlarged arch ends with bending joints. Details of these configurations and their underlying mechanism are to be provided below.

2.2.1. Artificial Short Joints at Downstream Surface. Contrasting to the conventional intact and stiff arch configuration, short joints were purposely built in Shimenzi arch dam contributing to the formation of flexible-arch configurations. The locations of these joints were carefully designed and the two trisection points of the downstream surface (Figure 3) were considered in the actual practice. These two short joints were aligned along the radial direction and took a depth of $1.5 \mathrm{~m}$. The purpose of the arrangements of these two artificial joints is to decrease the tensile stress along the arch direction on the central downstream surface under the reservoir pressure and temperature drop loads in cold seasons.

2.2.2. Hinged Well Configuration at the Middle Contraction Joint. Normally, quite a number of contraction joints are to be implemented during the construction of arch dams for the purpose of temperature control and the minimization of thermal cracks induced damage to the integrity of the whole dam. However, these contraction joints will impede the construction process and increase the length of schedule. In order to achieve a continuous placement of roller compacted concrete using a large working area, only one transverse joint along the crown cantilever section was implemented in Shimenzi arch dam, which can improve the temperature control and in turn the thermal stress buildup in the dam concrete to a certain extent. Furthermore, a hinged well configuration made of expansive-type concrete was applied in the upstream part of the contraction joint (Figure 3).

Such a configuration, together with water-stop measure on its upstream side, can enhance the continuous force transfer along the arch direction under the reservoir loads; hence, an earlier impounding of reservoir can be achieved ahead of schedule. It should also be noted that, for increasing the integrity of the arch structure, the main portion of the middle contraction joint (below $1380 \mathrm{~m}$ level) was grouted after the heat generation by hydration process dissipated sufficiently and fulfilled the sealing requirements, whilst a small portion near the dam crest (1380 1394 m level) has not been sealed by grouting finally, serving the purpose of lowering thermal stress in the upper dam part during operation stage and the improvement of cantilever tensile stress distribution on the middle downstream surface by the reservoir pressure induced bending deformation.

2.2.3. Enlarged Arch Ends with Bent Joints. The third measure for achieving flexible-arch configurations is to enlarge the two sides of each arch layer close to the abutments and to arrange two bending joints at the upstream corners (Figure 4). Two pads made of normal concrete were built between the dam concrete and the abutment rocks, and the directions of the two joints forming a contact surface with the pads turned from radial direction to nearly streamline direction. The length of these side joints was in a range of $2 \sim 4 \mathrm{~m}$. It should be emphasized that a specific type of soft material, which was mainly made up of architectural asphalt, was installed into the above purposely built short joints.

Reasonably the enlargement of the arch ends can increase the contact surface area between the dam and the rock abutments, which can provide additional safety margin in terms of sliding along the dam-abutment interface. The aim of the two short joints arrangements near both abutments was to lower the tensile stress concentration caused by upstream water pressure and thermal loads. Importantly, the length of these two joints was chosen to be long enough extending downwards into the low tension zone. On the function of the soft materials embedded into the joints, they are relatively more deformable due to their lower stiffness and can adjust easily to the localized response near the dam abutments, which can significantly improve the tensile arch stress distribution. On the other hand, it should be noted that such a band of soft materials may induce greater dam displacements as compared to the common case of an intact arch configuration. Furthermore, such a configuration of enlarged arch ends with bending joints can lower the discrepancy of the displacements between adjacent arch layers, which can in turn benefit the control of tensile cantilever stress in the downstream part of the dam.

Similarly as other artificial joints, water-stop measures were installed near the upstream openings of the joints, and a channel steel beam (no. 16 of the GB50017-2003 standard) was 


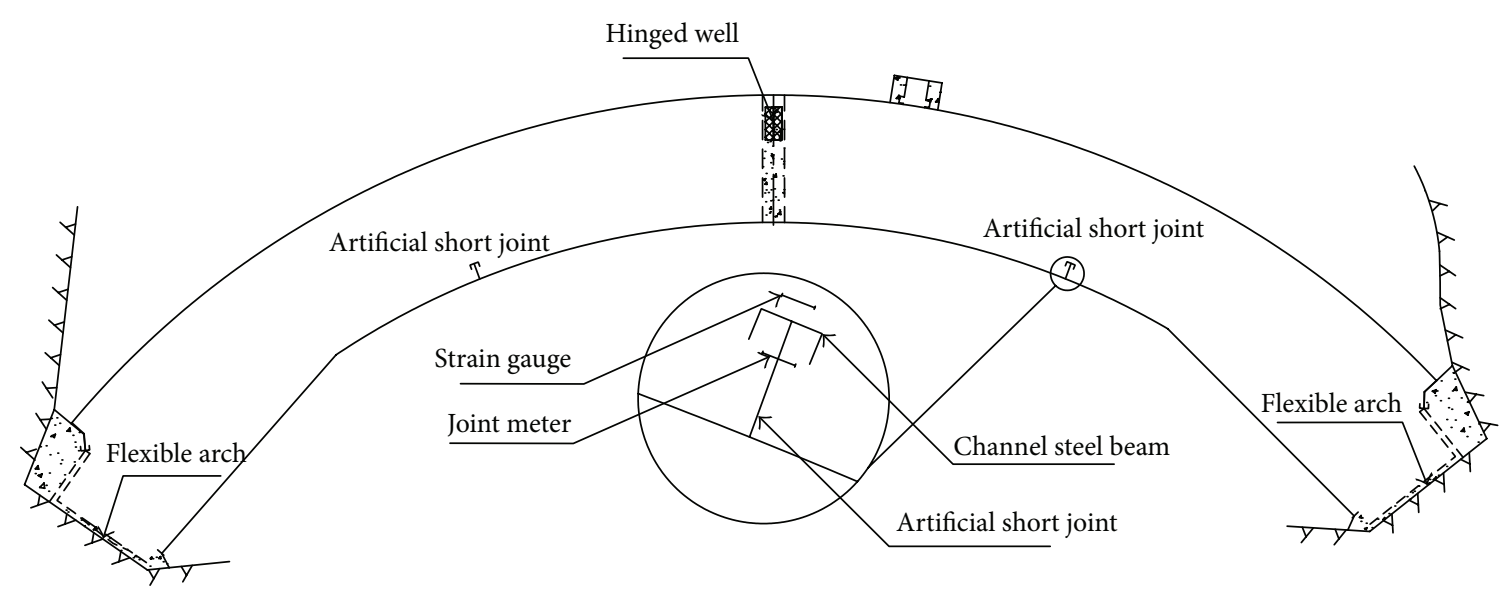

FIgURE 3: Layout of artificial short joints in Shimenzi arch dam (1360 mm layer as an instance).

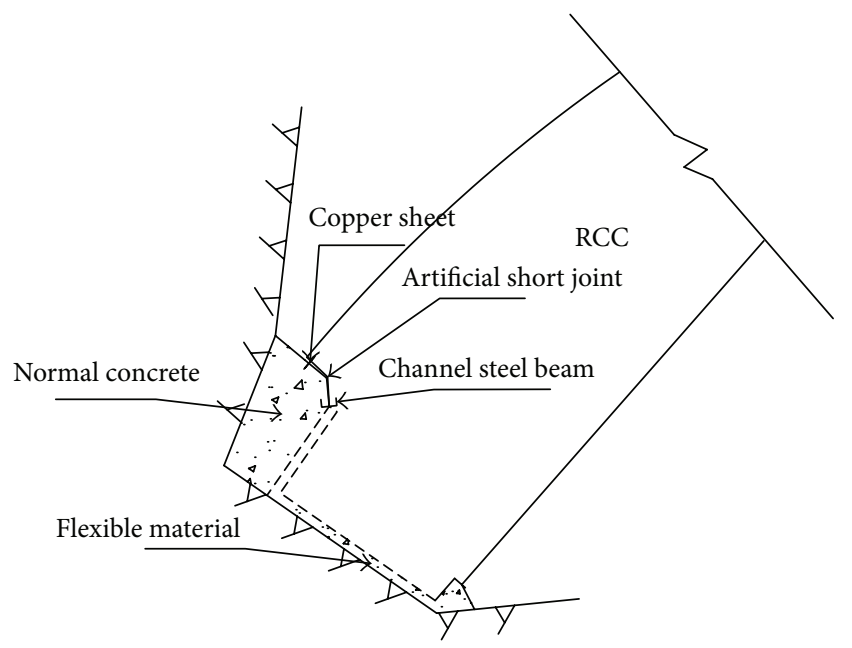

FIgURE 4: Detailed layout of enlarged arch ends with bending joints.

embedded into the dam concrete for minimizing the possible propagation of the joints into downstream dam part.

\section{Contributions of Flexible-Arch Configurations by Field Measurements}

3.1. The Effect of Artificial Short Joints. As mentioned above, the installment of artificial joints on the downstream face was aimed at lowering the mobilized tensile stress along the arch direction by the upstream reservoir pressure and thermal drop loads. Here, we will look into the contributions of these joints by the field measurements of joint meters and strain gauges, which were, respectively, installed at the mouth of the joints and at the upstream side of the channel steel beam (Figure 3). Particularly, the strain gauges were arranged normally to the joint direction.

The joint meter measurements demonstrated that as the impounding began, the two artificial joints were prompted with openings instantly. Some of the joint meters failed due to large magnitudes of opening that exceeded the measuring

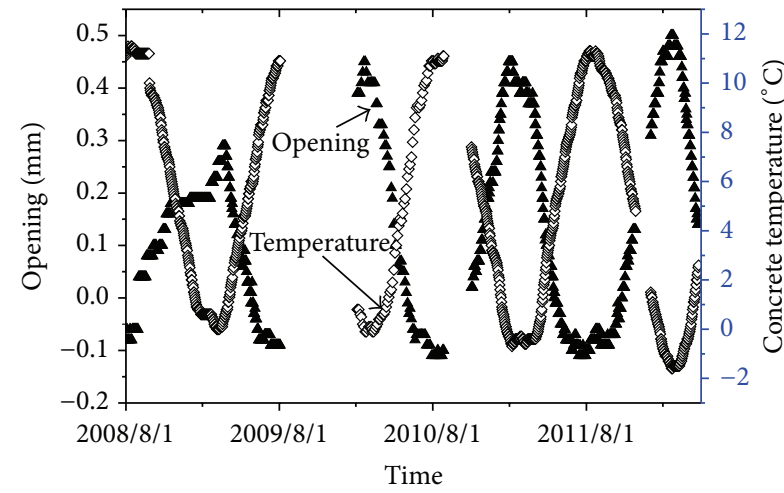

FIGURE 5: Time variation of joint opening at the left short joint at $1360 \mathrm{~m}$ elevation.

span. Figure 5 illustrates the readings of one successful joint meter from August 2008 to May 2012, and the temperature of the concrete nearby is shown with them. It can be seen that the time variations of joint openings and concrete temperature are reasonably out of phase. With the concrete temperature dropping in the winter seasons, the dam showed a deformation trend of contraction and the two artificial joints showed larger openings. Easily a contrary trend can be seen from the readings in the hot summer seasons. It can also be observed from the measurements that the maximum joint openings remained basically the same during the past several years, which may indicate that the channel steel beam can efficiently retard the propagation of the joints, which is really important for the overall safety of Shimenzi arch dam.

A typical range of the strain gauge readings at the upstream side of the channel steel beam from June 2003 to July 2008 is shown in Figure 6. The concrete temperature around is also shown for comparison. It can be seen that as the location of the strain gauge was relatively deeper into the dam in comparison to the joint meter (Figure 3), the temperature here showed a prominent lag with the change of air temperature. However, it can also be seen that the strain gauge readings and the concrete temperature data are again 


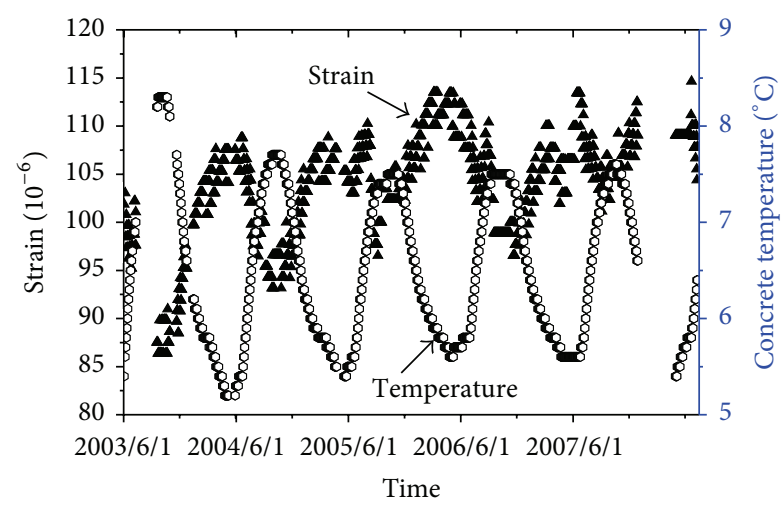

FIGURE 6: Time variation of strain gauge readings at the upstream side of the left short joint at $1360 \mathrm{~m}$ elevation.

out of phase as the above joint meter data. The observations are reasonable considering the significant influence of thermal loads induced volumetric deformation within the whole arch dam. One can note that the measured strain component normal to the joint direction kept compressive, falling in a range of $80 \sim 115 \mu \varepsilon$, which may again imply the effectiveness of the channel steel beam measure in resisting the extension of the artificial joints.

3.2. The Effect of Middle Joint with Hinged Well. Similarly a set of joint meters were installed at both the upstream and downstream sides of the middle contraction joint. From the readings during the construction stage, it was found that joint openings at the upstream side presented an increase trend until the initiation of impounding (December 2000), and the peak value was $2.0 \mathrm{~mm}$, which was deemed to be mainly induced by temperature drop loads. In the subsequent stages, the upstream openings presented a minor fluctuation, falling in a range of $0.4 \mathrm{~mm}$ in amplitude, and the following data fell on a nearly horizontal line after the reservoir was impounded to a certain water level.

For the joint meters at the downstream side, the readings also presented an obvious increase during the early construction stage, which resulted from temperature drop loads. These readings continued to increase after the impounding began. In May 2001, the maximum reading was $3.41 \mathrm{~mm}$. The measurements then returned to a certain extent in response to the lowering of water level. From April 2002, the openings reached a peak value of $3.8 \mathrm{~mm}$ and the subsequent data only showed minor changes (lower than $0.5 \mathrm{~mm}$ in amplitude) with the increase of water level in winter seasons.

Figure 7 presents a comparison of typical joint readings from August 2008 to May 2012, and the concrete temperature in the vicinity of the joint meters was shown also for comparison. It can be clearly seen that, with the impounded reservoir, the upstream openings of the middle joint were significantly lower than those of downstream side. The upstream data remained nearly on one horizontal line, which may indicate that, with the hinged well component installed, the relative deformation near the upstream side of the middle dam portion remained stable under various water levels

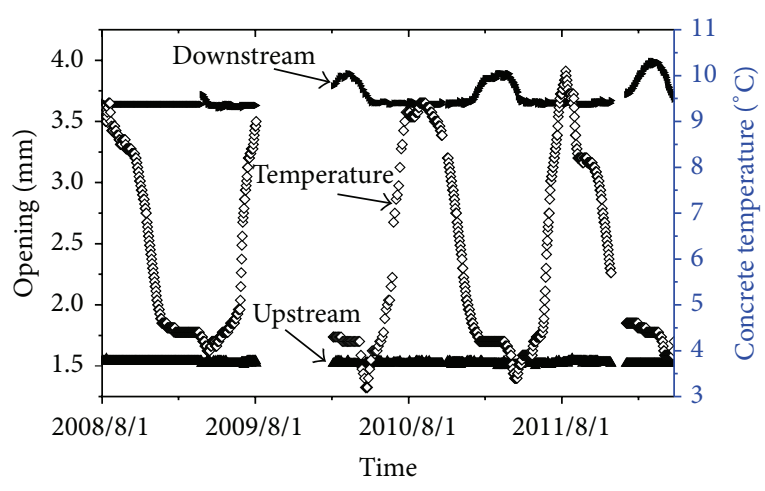

FIGURE 7: Time variation of joint openings at the upstream and downstream sides of the middle contraction joint at $1360 \mathrm{~m}$ elevation.

during the aforementioned four years. On the other hand, the downstream readings showed that a prominent increase was mobilized annually during the winter seasons, which can be a combined effect of temperature drop loads and water level uplift in the cold seasons. It seems that the annual increase amplitude of joint openings at the downstream side remained nearly constant in the four years.

3.3. The Effect of Enlarged Arch Ends with Bending Joints. For the bending joints across the interface between the arch ends and the pads on the rock abutments, joints meters have also been arranged for monitoring the possible openings (Figure 4). Figure 8 presents a comparison of the joint opening data and the adjacent concrete temperature at the left arch end of $1360 \mathrm{~m}$ level. The typical data from June 2000 to June 2004 were chosen and plotted in the figure. Strong relativity can be seen from the variations of the two curves. When the concrete temperature decreased, the measured joint openings were prompted with an increase and vice versa. The measurement data prove the effectiveness of the bending joints for stress release along the arch direction under temperature drop loads. It can be seen that the joint readings started to be positive from October 2000, in which month the impounding process was initiated. During the following half year the opening increased abruptly and up to $0.6 \mathrm{~mm}$. The fluctuation amplitude of the opening remained at about $0.2 \mathrm{~mm}$ during the following years, which may indicate the good working conditions of these bending joints.

Moreover, it was found from the readings of the strain gauges at the downstream side of the channel steel beam that the corresponding concrete portion remained compressive. This indicated that the channel steel beam measure can retard the propagation of the prescribed bending joints, even under the worst working conditions during the past ten-year-long operations.

\section{Discussions}

Through a comprehensive investigation into the field monitoring data, including the readings from joint meters, strain gauges, thermometers, and water level recorders, the 


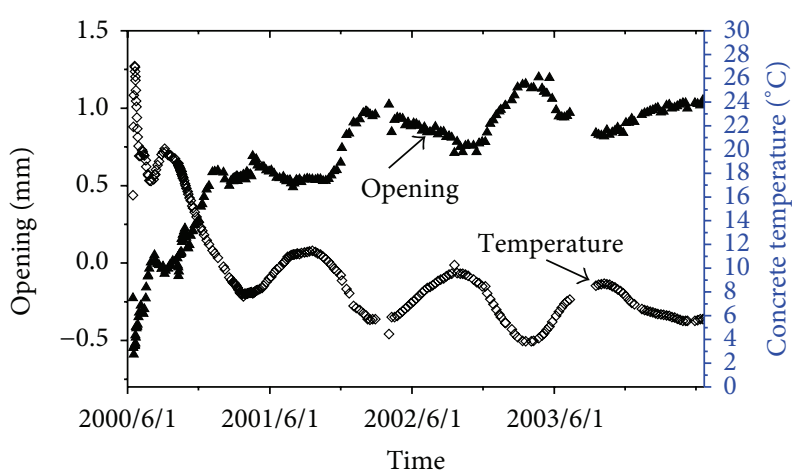

Figure 8: Time variation of joint openings at the short joint at the left arch end of $1360 \mathrm{~m}$ elevation.

flexible-arch configurations developed by the Department of Hydraulic Engineering have been shown to be working properly and can effectively improve the stress performance of Shimenzi arch dam. The artificial short joints presented openings within a certain limit, even under the worst working conditions, which showed the effectiveness of the joints for tensile stress relaxation in the middle downstream portion. The middle joint also performed well at the critical situation under temperature drop loads, whilst the hinged well configuration can support the arch force transfer under reservoir loads. The effectiveness of the bending joints at both arch ends could also be proved by the finite opening that remained stable during the long-term operations. Particularly, the potential extension of these purposely built short joints, plane or with bending, may severely threaten the safety of the arch dam. The monitoring data showed that the channel steel beam measure arranged ahead of the joint tips could effectively resist the development of crack propagation. Moreover, recent field survey data showed that the occurrence of cracks is quite low in the dam. Overall, Shimenzi arch dam performed well with the flexible-arch configurations during the construction and long-time operation stages.

For a better look at the contributions of artificial joints on the stress redistribution, a set of plane-strain arch structure models were established based on the finite element method. The arch layer at $1360 \mathrm{~m}$ level was chosen, and a fixed boundary condition was assumed at the arch-foundation boundaries. Three numerical cases were considered. In Case I model, an intact arch structure with no joint was assumed. Case II model incorporated a short joint of $1.0 \mathrm{~m}$ long at the middle downstream side and two side joints of $1.5 \mathrm{~m}$ long at both arch ends. In Case III model, the side joints remained, whilst the middle joint was extended to $1.5 \mathrm{~m}$ length and another short joint of $0.5 \mathrm{~m}$ was arranged at the middle upstream side.

A temperature drop load of $10^{\circ} \mathrm{C}$ constantly distributed in the arch structure was considered for each model, and the resultant principal tensile stress distributions are compared in Figure 9. It was found that the different arrangements of the short joints can significantly influence the tensile stress mobilization. As given by Figure 9(a), the tensile stress zones for Case I model are located at both ends of the arch structure and the middle downstream portion. The pattern is consistent with the distribution of thermal cracks that are commonly observed in prototype arch dams. The maximum tensile stress is 3.0 MPa for such an intact arch structure and located at both upstream corners. From Case II model, the tensile stress zones are also at the upstream arch ends and the middle downstream portion (Figure 9(b)). The maximum tensile stress, again mobilized at both upstream corners at a value of $2.8 \mathrm{MPa}$, is relatively smaller. It should be noted that the stress distribution is improved and the tension zones in the vicinity of all joints are much smaller than in Case I. Figure 9(c) presents the results for Case III model. A comparatively smaller tension zone is mobilized at the middle downstream side, and the effect of a longer downstream middle joint and the addition of a short joint at the upstream counterpart is shown to be limited within the local central part. On the other hand, the short middle joint at the upstream surface does not introduce any unfavorable tension zone as expected.

The above analysis results again demonstrate the effectiveness of artificial joints on the improvements of tensile stress distribution and in turn the lowering of cracks potential. These findings are also consistent with the previous reports by Liu et al. [10, 11]. Their modeling on a plane arch structure subjected to upstream water pressure and temperature drop loads also proved that the introduction of short joints at both arch ends could lower the tensile stress concentration near the upstream arch corners, and the stress intensity factor can be lowered to below $0.4 \mathrm{MPa} \cdot \mathrm{m}^{1 / 2}$ by an arrangement of $10 \mathrm{~m}$ long joint at the middle downstream face.

It should be emphasized here that much attention should be paid to the choices of joint location and length, which can definitely influence the contributions of such type of artificial joints. The selection criteria of the joint location will be based on the geometry of arch dam and the extreme working conditions. For a joint of tiny length, its function for tensile stress relaxation may be minor and not effective. But a joint too long in length may induce instability of crack propagation and threaten the safety of dam structure. Optimization numerical study based on the finite element method is recommended for the selections of joint location and length in each dam individually.

\section{Concluding Remarks}

A retrospective study at the flexible-arch configurations in Shimenzi arch dam is given in this paper. The past ten-yearlong field measurement data, particularly those from joint meters, strain gauges, and thermometers, have been chosen for an investigation into the contributions of the main components forming the flexible-arch configurations. Based on the monitoring data as well as some fundamental numerical analyses, the following remarks have been concluded.

(1) The arrangement of short joints at the trisection points of the downstream surface can effectively lower the tensile stress mobilized at this zone by the temperature drop loads. The bending joints embedded at both arch ends can significantly weaken the strong 


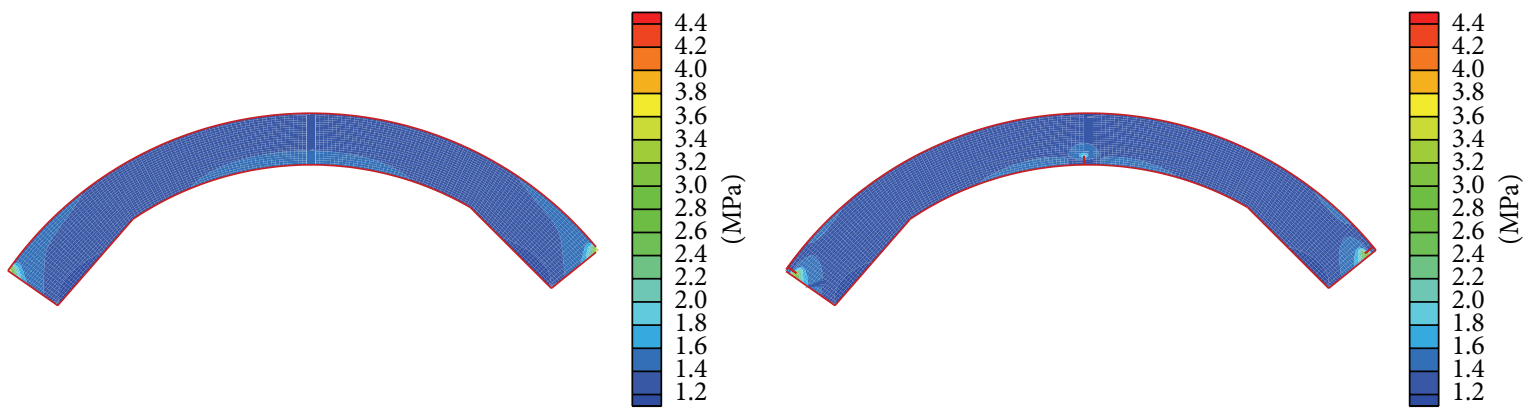

(a) Case I model

(b) Case II model

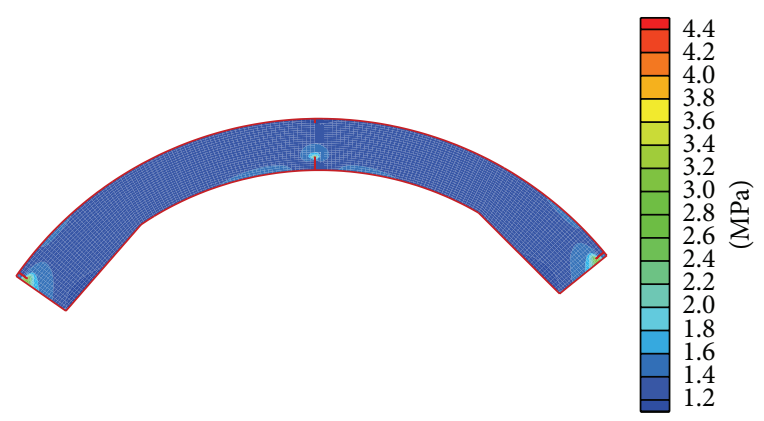

(c) Case III model

FIGURE 9: Comparison of principal tensile stress distribution for a plane arch structure with different joint arrangements subjected to constant temperature drop loads.

constraint from rock abutments and can in turn decrease the tensile stress concentration.

(2) The middle contraction joint with hinged well configuration can increase the flexibility of each arch layer, lower the tensile stress caused by upstream reservoir loads, and maintain a continuous arch force transfer during construction stages, which resultantly can shorten the time schedule and achieve early impounding.

(3) The treatments of these purposely built short joints need careful consideration to avoid potential crack propagation. The installments of channel steel beams ahead of the tips of each joint in Shimenzi arch dam were shown to be successful in resisting extension of artificial joints into the dam concrete.

There is a huge amount of field measurement data from Shimenzi arch dam, such as the dam displacements, internal stress, and temperature distributions. More indepth investigation into the past long-term operation of this dam is still necessary and can be of great significance for understanding the performance of the developed flexiblearch configurations, which are to be presented in the coming publications.

\section{Conflict of Interests}

This statement is to declare that the authors of this paper do not possess any financial relationships that might bias their work. They hereby declare that no conflict of interests exists in their work.

\section{Acknowledgments}

The authors would like to acknowledge the support by the National Basic Research Program of China under Grant no. 2013CB035903, by the National Natural Science Foundation of China under Grant no. U1361103, and partial support by the State key Laboratory of Hydroscience and Engineering under Grant no. 2013-KY-02.

\section{References}

[1] H. Chanson and D. P. James, Historical Development of Arch Dams: From Cut-Stone Arches to Modern Concrete Designs, vol. 43, Australian Civil Engineering Transactions, Institution of Engineers, Melbourne, Australia, 2002.

[2] D. D. Maken, P. Léger, and S. N. Roth, "Seasonal thermal cracking of concrete dams in northern regions," Journal of Performance of Constructed Facilities, 2013.

[3] H. N. Linsbauer, A. R. Ingraffea, H. P. Rossmanith, and P. A. Wawrzynek, "Simulation of cracking in large arch dam-part I," Journal of Structural Engineering, vol. 115, no. 7, pp. 1599-1615, 1989.

[4] H. N. Linsbauer, A. R. Ingraffea, H. P. Rossmanith, and P. A. Wawrzynek, "Simulation of cracking in large arch dam-part II," Journal of Structural Engineering, vol. 115, no. 7, pp. 1616$1630,1989$.

[5] L. M. Feng, O. A. Pekau, and C. H. Zhang, "Cracking analysis of arch dams by 3D boundary element method," Journal of Structural Engineering, vol. 122, no. 6, pp. 691-699, 1996.

[6] A. C. Teusdea, T. Modog, D. Gombos et al., Fourier Correlations of Dragan Dam Horizontal Deformation Id and $2 d$ Time Series, Annals of Daaam \& Proceedings, 2009. 
[7] D. J. Philippon, "Edward abbey's remarks at the cracking of glen canyon dam," Interdisciplinary Studies in Literature and Environment, vol. 11, no. 2, pp. 161-166, 2004.

[8] Portuguese National Commission Working Group, "Cracking and repair works in cabril dam," in Proceedings of the 15th International Congress on Large Dams, vol. 57, Lausanne, Switzerland, 1985.

[9] B. Zhu, "On the feasibility of building high quality arch dams without cracking and the relevant techniques," Journal of Hydraulic Engineering, vol. 37, no. 10, pp. 1155-1162, 2006 (Chinese).

[10] G. T. Liu, S. N. Xie, P. H. Li et al., "Effect of artificial short joints on stress relaxation and cracking control in RCC arch dam," Journal of Hydraulic Engineering, vol. 5, pp. 9-14, 2002 (Chinese).

[11] G. T. Liu, G. X. Zhang, and Z. H. Liu, "Simulation stresses of RCC arch dam with transverse joints and biaxial strength criteria," Journal of Tsinghua University, vol. 36, no. 1, pp. 13-19, 1996 (Chinese). 


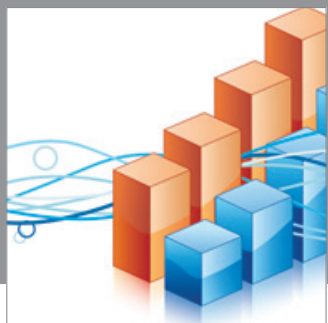

Advances in

Operations Research

mansans

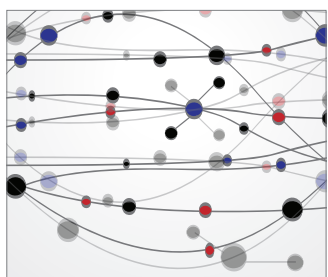

The Scientific World Journal
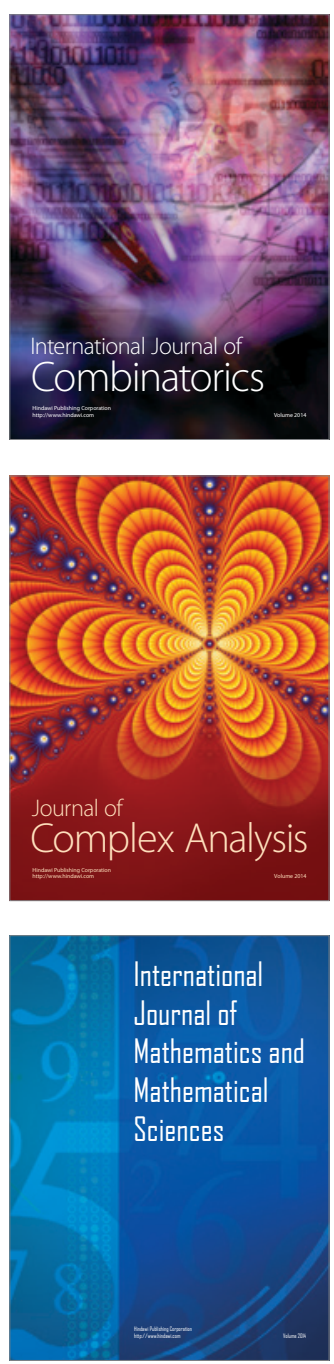
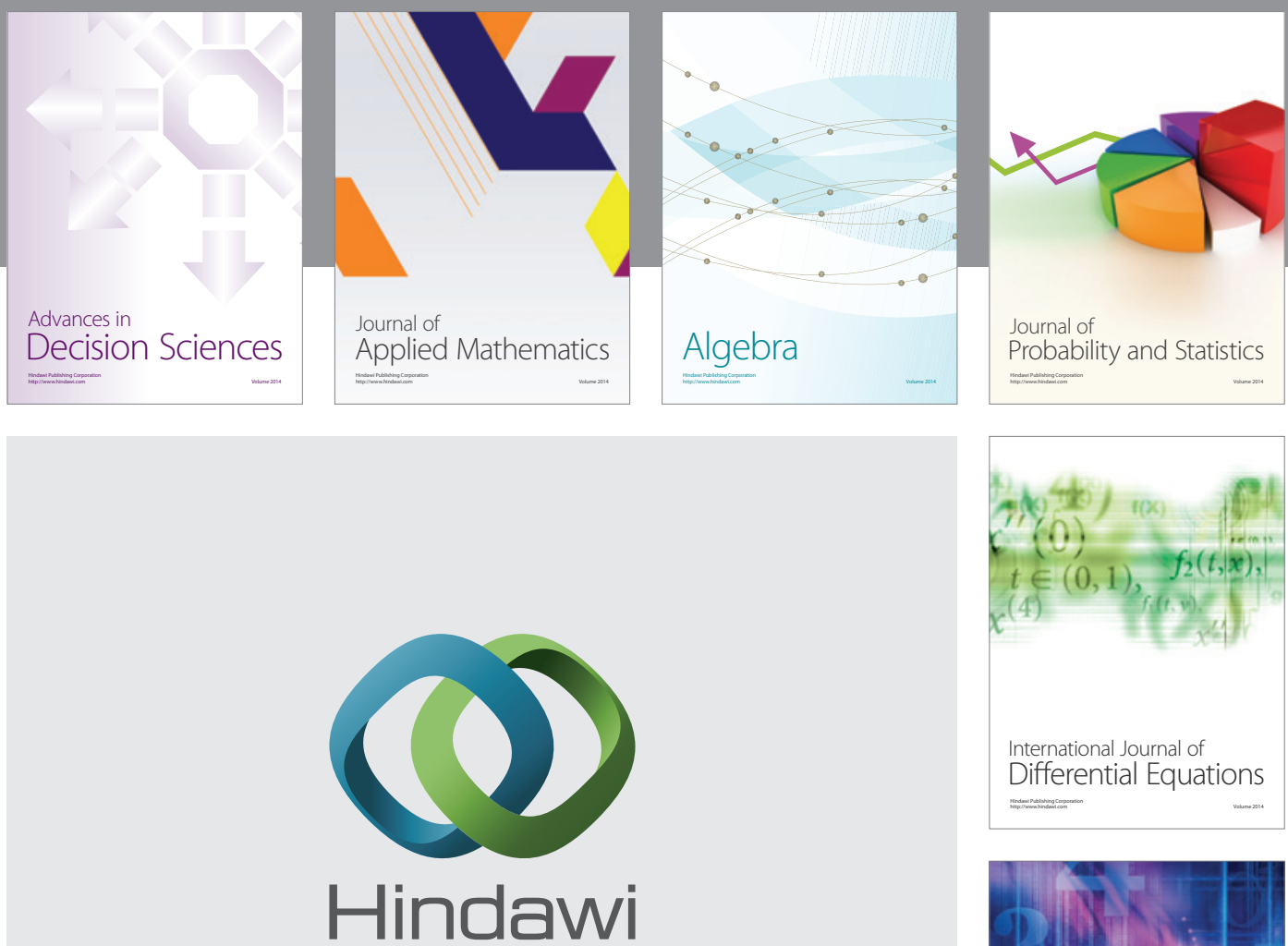

Submit your manuscripts at http://www.hindawi.com
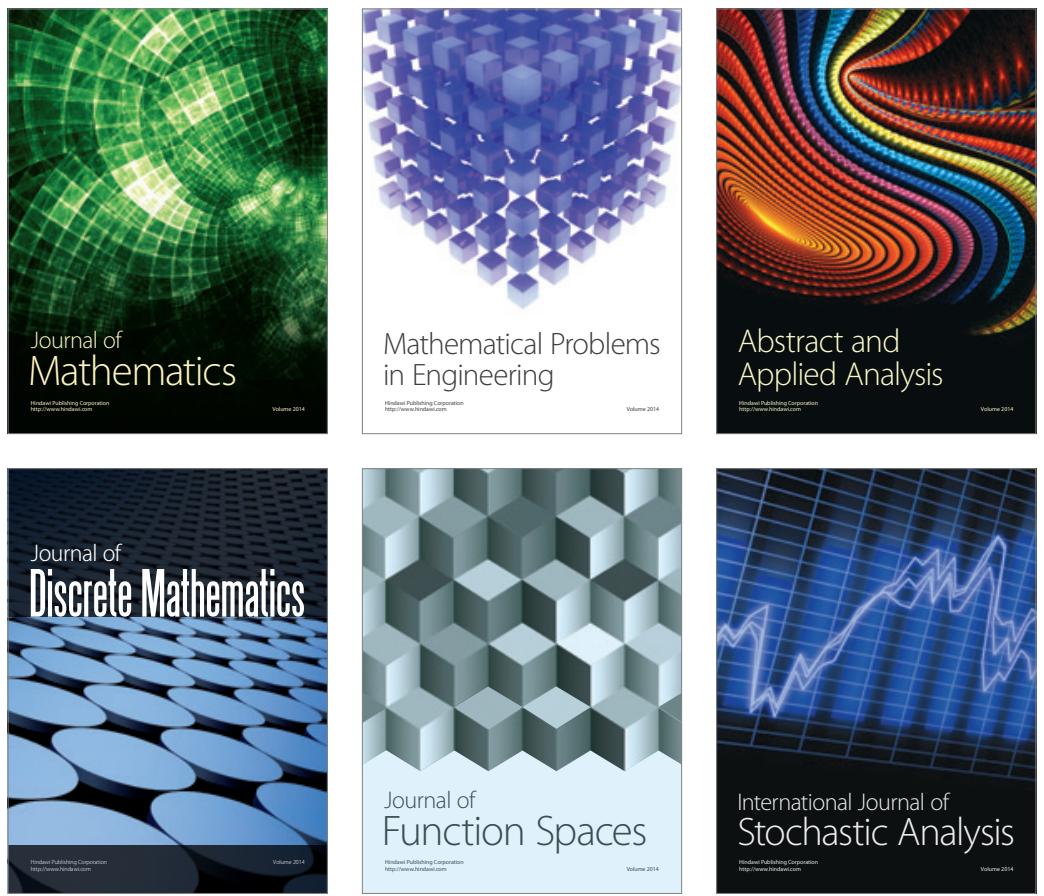

Journal of

Function Spaces

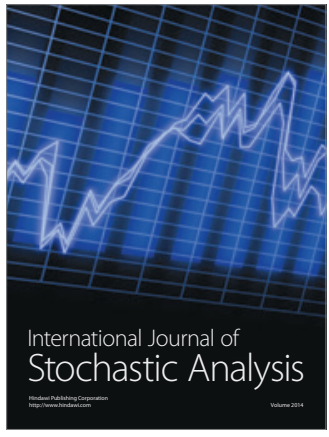

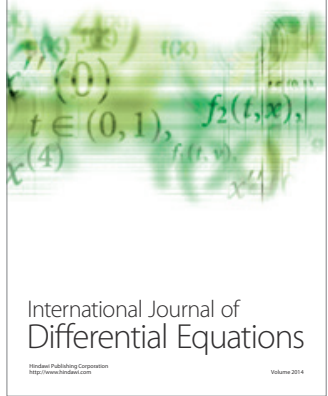
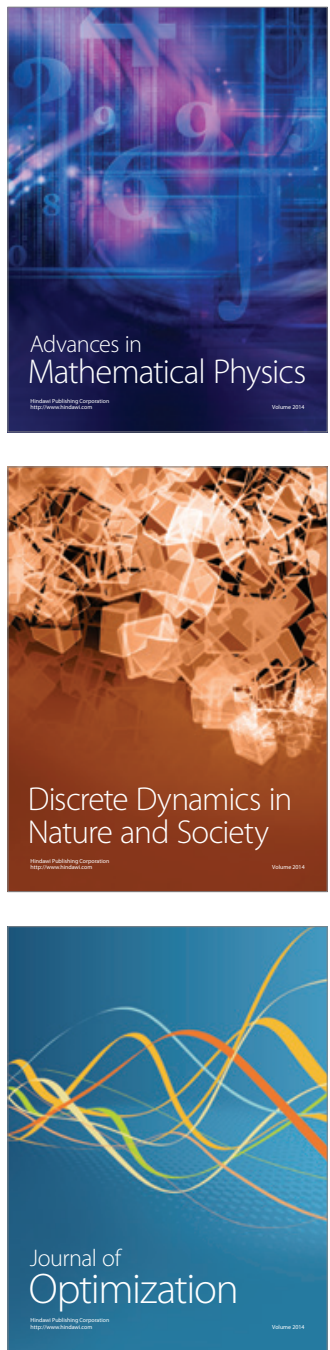